\title{
Creative Endeavors: Inspiring Creativity in a First Grade Classroom
}

\author{
Susan W. Cress ${ }^{1} \cdot$ Daniel T. Holm ${ }^{1}$
}

Published online: 1 April 2015

(c) Springer Science+Business Media New York 2015

\begin{abstract}
With an emphasis on high-stakes testing and a focused curriculum, it would seem at times, the joy of creativity is missing from the classroom. This article describes a curricular approach the children named "Creative Endeavors", as implemented by a first grade teacher. The approach is described in three phases. In the exploratory stage the children were presented with various media, made requests for additional materials, and explored different forms of expression. In the second phase the children made choices based on interests, and typically worked with others in a spirit of collaboration with an emphasis on the process of the project as well as affective responses. In the final phase of intentional planning, children began to independently design, construct, and take responsibility for their project working alone or with others. Phases are intended to provide a blueprint for other teachers to explore creative endeavors in the classroom. Children in this project communicated through various media including sewing, photography, and drama. Through collaborating with peer and choosing projects, the children became authentically engaged in the various classroom experiences. Although the curricular approach was intended to foster creativity, in each phase writing about their projects became a natural and critical element in the process. Children wrote about their experiences, the steps they took to take part in the process, why they chose it, and reflected upon the projects undertaken.
\end{abstract}

Susan W. Cress

scress@iusb.edu

1 Elementary Education, School of Education, Indiana University South Bend, PO Box 7111, 1700 Mishawaka Ave., South Bend, IN 46634-71111, USA
Keywords Creativity - Curriculum · Joy · Writing · Collaboration - Choice $\cdot$ Authentic engagement

At cratved indavers (creative endeavors) at yoga I lernd (learned) all of the yoga cards, but my teacher said have you ben (been) practicing the to (two) yoga cards. I for (thought) I could do more yoga things. Yaester (yesterday) I did frtogrfe (photography), me $\mathrm{L}$ and $\mathrm{A}$ we got to go up the stares (stairs) in the science lab and there where (were) a lot of inchsting (interesting) thing's. - writing of a first grader

What inspires this written reflection about Yoga? You only have to peek into Ms. P.'s first grade classroom, to feel the sense of excitement as the first graders eagerly await a very special part of their day, that the children named "Creative Endeavors".

In classrooms around the country, there seems to be a fragile hold on creativity; a reluctance to step away from scripted, test-based instruction to meet state standards. This is problematic as Nichols and Berliner (2008) view the narrowing of the curriculum, the focus on high-stakes testing, and "artificial goals" (Ward and Dahlmeier 2011) as taking the joy out of learning. However, when supported by administrators and families, teachers are able to reach beyond a test-driven, standards based curriculum so prevalent in classrooms, and tap into creativity as a crucial part of the learning process. Helm (2008) noted, engaged students can still have an enjoyable learning experience while meeting the standards. One such approach is Creative Endeavors, a teacher developed curricular approach which, in $1 \mathrm{~h}$ a day, elicited excitement and motivation in a class of first grade students to excel in the use of different artistic media and writing forms while communicating with peers and adults in a way which goes beyond simply meeting the standards. 
What was the impetus for Creative Endeavors? The idea began to percolate right before winter break as Ms. P. stood at the smart board while the children dictated a poem to her entitled, "The Night before Christmas Vacation." As the children eagerly dictated a portion of the poem to imitate the more traditional "Night Before Christmas," the teacher took note of the enthusiasm as the children drafted and revised their version. The children took turns dictating the poem, revising each other's attempts to provide a new piece, while discussing the vocabulary used, and deciding on the punctuation needed to make it more readable. The collaborative process notably engaged the children in the creativity of writing.

Ms. P. began to wonder how she could capture this excitement as a part of their everyday curriculum. She began to wonder what other choices could be made available to the children to capture the excitement of this before break activity. Could such examples of creativity be inspired through choice, collaboration, and scaffolding with interested peers and the teacher? Could this be captured in the drawings and writings of children?

\section{Creativity and Young Children}

In an attempt to define creativity, The Robinson Report (National Advisory Committee on Creative and Cultural Education 1999) describes the development of creativity as an area where all people can be successful in the creative process. Sharp (2004) concurs, "When considering young children, it is appropriate to adopt a broad, democratic definition of creativity. In this way every child can be considered to have creative potential and to be capable of creative expression." (p. 6). Glaveanu (2010) writes of an expanded type of creativity. Rather than the individual creativity in a traditional sense he writes of a need to develop creativity where collaboration is the key in the creative process.

Perhaps the greatest example of democratic and collaborative creativity comes from the Reggio Emilia schools. The work of Malaguzzi, the founding educator in the Reggio Emilia schools of Italy (Edwards et al. 1998) where the project approach has been implemented since the 1940s, suggests that young children in the proper environment, with the appropriate materials, collaborative peers, and supportive adults are capable of high levels of creativity. Children in the Reggio Emilia schools take part in in-depth projects that are sustained over time. A critical element in the projects is symbolic representation of the process that is represented through much discussion, collaboration with peers, and the arts.

Research on creativity, embedded in policy, stems from England's National Foundation for Educational Research
(NFER). The research comes as a result of a national policy, beginning in 1999, to engage children in creativity throughout the primary curriculum through the implementation of partnerships with the artistic community (Sharp et al. 2006). Children visited cultural sites, worked with the people in the arts, and participated in artistic endeavors. As creative partnerships developed, students were able to engage in projects sustained over a period of time, with an emphasis on process rather than products. In a discussion of results of the research Sharp et al. (2006) states: "Creative Partnerships projects provided an enjoyable experience, helped to develop creative learning and raised the profile of creativity and arts in schools." (Sharp et al. 2006, p. 42).

In a study conducted in Denmark, Tanggaard (2011) describes the need for creativity in the workplace to foster new ideas within the larger community and society. In Tanggard's research the focus was on examining teachers' concepts of creativity, and developing creativity through their teaching. In speaking of creativity "From the teachers' statements, creativity, meaning that things develop or grow in new and unexpected directions seem to emerge rapidly, given the right conditions." (p. 228). Common themes resulting from the research indicated that teachers need to be open to trying new ideas in teaching and indeed function as role models and mentors.

Connors (2013) writes about the scarcity of opportunities for children to develop creativity. "With so much time in school being focused away from creativity, we need to balance this with time spent on developing more creative ways of thinking-time when children can experience themselves as creative thinkers and when we encourage and support them. Children need opportunities to effectively communicate their creative ideas in a group setting." (p. 1). While the content matter in this article is related to music she provides the following tips for teachers in order to develop creative thinking. (1) Create an environment of respect with a positive classroom climate so that children feel safe to express themselves in a group setting with new ideas supported or scaffolded by the teacher. (2) Offer experiences which are new and challenging, and (3) use encouragement of new ideas rather than praise.

Robson and Rowe Webb (2012) examined the creativity of young children through "child-initiated, adult-directed and adult-led activities in an early childhood setting." (p. 349). The research suggests that child-initiated activities are heavily dependent on an environment and teachers who support their exploration of various media and resources. Furthermore, the child-initiated activities involve the children at the highest levels, especially with other children. Adult involvement is most pertinent when new ideas are introduced; however, the child interactions with peers more often support higher levels of interactions than those 
between adults and children. Another result considers the persistence in play that is most evident when it is child initiated, but supported by adults.

Miranda (2015) speaks to the role of teachers and suggests they look to their own creative imagination to find and plan strategies which will both engage young children and allow them to use music and drama in learning. She points out that while we think of ourselves as fairly creative and flexible, teacher-directed activities often take precedence due to curriculum and societal expectations. Miranda suggests that teachers provide manipulatives for symbolic play, (e.g., unit blocks being used for food in the cooking area). The object then acts as an impetus to more imaginative play. She also points to the flexibility of time for extension of play, or time to revisit the experience on another day.

Although much of the work on creativity is directed at the arts, in research directed towards creativity and science, Webb (2012) addresses creativity in relationship to problem-solving. Webb sees this as a way to provide children with problem solving as a life-long skill in employment. She states that teachers support creative experiences, but are uncertain as to how to integrate them with the content areas. In the study there was an initial negative proclivity towards the perceived more difficult creative task, rather than the directed task. However, both were seen as enjoyable. In the creative task results indicated there was a positive effect on vocabulary acquisition, but Webb suggests that more experiences with integrating content learning with creativity might lead to an increase in both enjoyment and learning.

In a review of three studies on technology and how children use technology and digital toys and games McPake Plowman, and Stephen (2013) found that these technologies might well enhance creativity and communication. Given that the children are all in preschool during the study the implication is that before they even reach formal schooling they will have developed some skills in the creative use of technology which will stay with them throughout their lifetimes.

The research clearly supports the development of creativity through a project based, collaborative process. The role of the adult is to encourage creativity through scaffolding of ideas, implementing their own novel approaches, offering a positive environment, and allowing the possibility of integrating various content areas into the creative process.

\section{Context for Creative Endeavors}

The school is located in the southeastern United States in a well-established suburban community. The school has been renovated in recent years and has smart board technology in each room. Seventy percent of the teachers have advanced degrees, as does the teacher in the classroom. All of the children attended full day kindergarten prior to entering first grade. School wide test scores are in the top tier for the state. The classroom was comprised of 13 girls and 11 boys. Approximately $15 \%$ of the students receive free or reduced lunch. The classroom is bright and cheery with many natural materials as well as the manipulatives one might expect in a first grade classroom. There are different areas of the room clearly labeled which allow the first graders independence in gathering and putting away materials. Desks are arranged in table groupings that help with collaboration as children go about their learning.

Mrs. P.'s goal was for her classroom to be a place where learning was joyful, exciting, and creative. She looked for ways to integrate writing into the process which she knew would enhance Creative Endeavors. To achieve her goal, the students engaged in three phases: exploratory, choices based on interests, and intentional planning and sharing by students. These three phases will be discussed here.

\section{Phase 1: Exploratory}

The first step involved finding media that would attract the attention of the children. Playdough, fingerpaint, tempura paint, stickers, scissors, and glue were the first materials presented. By the second week children asked for clay, beads, digital cameras, markers, puzzles, and pieces of cloth. During the first 2 weeks, children were intrinsically motivated to examine the art materials without specific intentions or products in mind. As children explored the materials and forms of expression such as drama, music, and yoga, ideas started to formulate into projects they would like to consider. At the end of this exploration phase a class meeting was held to discuss what additional supplies were needed to make their projects a reality. The addition of toothpicks, needles, and thread were added to the supply list.

During this time of experimentation, some guided practice into the different projects was given. In the first week some children decided on the job of making robots. The voice of each in a group of four describes the robot endeavor.

R. writes, "My teme was W. C. H. and me. The robot's names Fire Canin. Frst we got the stuf on a cofe (coffee) box. We put cardboard crcul (circles) on the box. Me and Will wanted to do our own robot but Ms. P. did not let us dow it. Me and W. put them in the arms."

The second participant, H. writes "First W. and Cat. Robert and me got a Cuisinart box and put buttons inside the box. Then we put a bottle inside. Our robot's name is Fire Canen and our robot will make a noise. It has cannons for arms. Our second robot is a bottle with Styrofoam inside it with popsicle sticks." 
The third collaborator, C. writes, "We made a robot with W. R. H. and me. We like our robot. It's cool. He has tornado arms. He has sharp teeth. His name is Fire Cannon."

W. is the fourth contributor. He writes, "Our robot has cans for the hands and feet. He has rockets on his feet. His name is Fire Cannon. He destroys strangers" (Fig. 1).

The four writings about the one group project all show the spirit of collaboration in the event, although R. did try to break out with W. to do their own. Each of the writings seem to impress on the audience what each child perceives to be important about their robot making. The sequence of the activity is clear in the first two participants descriptions, whereas, characteristics are depicted more with words such as "sharp teeth" and "He destroys strangers" in the next two written narratives.

The excitement of the robot and the process motivated the children's writing. Once the narrative was written, they were eager to move on to the next Creative Endeavor.

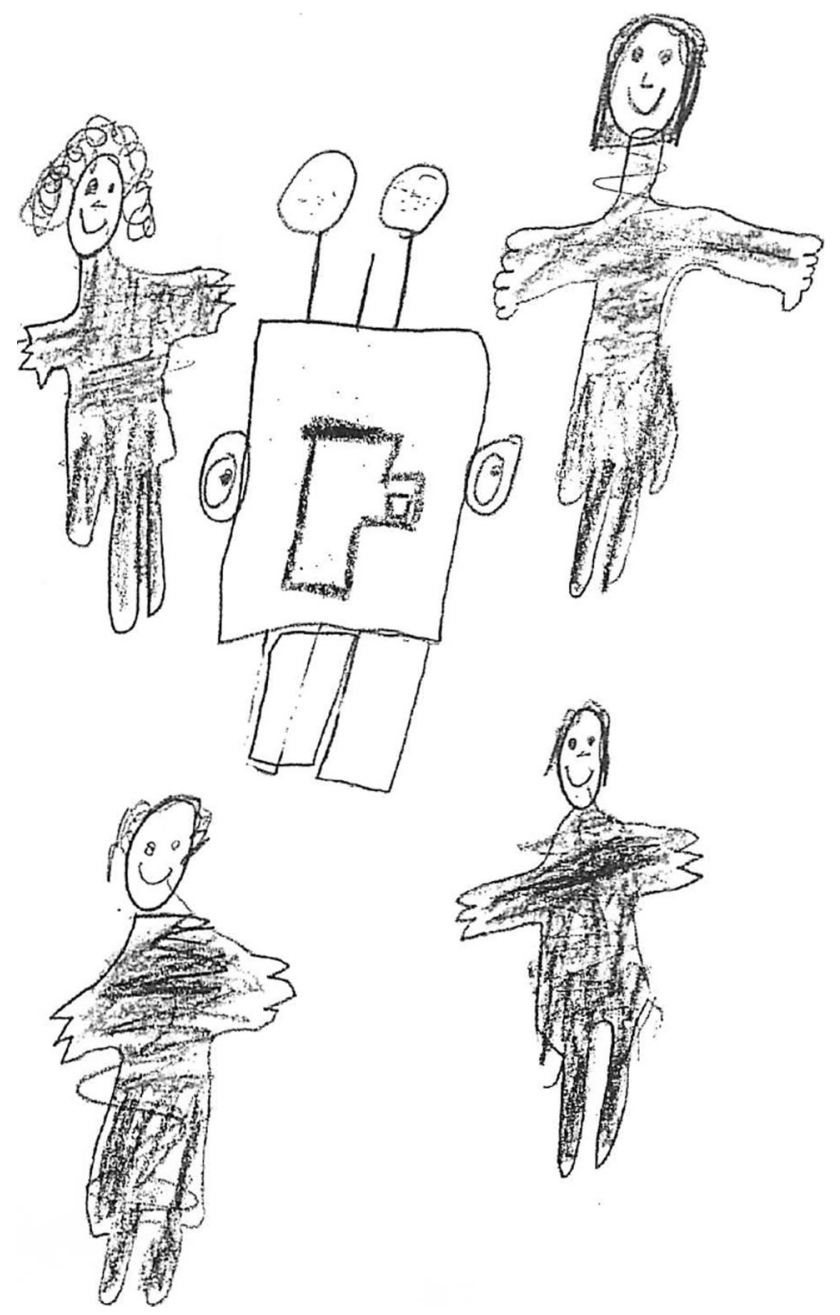

Fig. 1 Drawing of the group robot endeavor

\section{Phase Two: Choices Based on Interest}

After the exploratory phase, children began to work in groups of choice based on their interests. Early in the process, Ms. P. introduced the reflective piece. As they finished their project they would write about what they made, when they started it, steps to accomplish the project, why they chose it, and how it made you feel. The enthusiasm for the project is evident in their writing.

Highlighted here are children who began to create using sewing as their medium. Three children choose to make fabric pillows, two decided to make tooth pillows, and one designed an animal to sew. Two more children made heart pillows while two others finished decorating pillows started the week before during the exploration phase.

K. writes, "I went to sewing. It goes up and down. I made a heart. I have not suffed it. Ms. P. helped me. I am going to sewing. I am giving it to my MoM. My pillow will be cozy. It was hard and awesome. I Love sewing I am going to make a nother pillow. I love creative endeavors. Sewing rocks."

The drawing included with G.'s writing is detailed, another means of communication. You can clearly see where the machine started and stopped and sewing by hand finished it up (Fig. 2).

Other children created pictures and covers for their classroom chairs, again combining drawing with writing. R. writes, "First I drew with sharpie. Mrs. P. got the sewing mushen (machine) and sewed the chair back then I flipped it and put it on my chair."

Four children took up photography and ventured forth with the student teacher to document the rare snow event that happened over the weekend. Their subsequent writing about snow shows their interest in the topic and experience with it. The photography sparked the interest in writing about the snow.

S. writes with a sense of wimsy, "I am going to see snow. My frind is going to. Me and my frind miet (might) have a snowball fight. My frinds name is Huke. Me and Huke miet (might) bild a snowman and crash into it jist to be funny and to macke it fun. We miet macke it ugle. bekus me and Huke are funny."

In describing another snow venture L. writes, "This weekend I went to see snow. And my cozinz (cousins) ware there. Some snow was soft. Some snow was stek (sticky). I tride to make a snowman but the snow was to hard. Then I got to go to a nother place to see snow. The snow was not hard. so I throw snowballs at my sister and my dad. My mom was in the car. It was so fun. when I goded back home I wish I was stil there."

Photography and video experiences comprised another part of Creative Endeavors. An experience with video is 
Fig. 2 Drawing and narrative of G.'s sewing endeavor

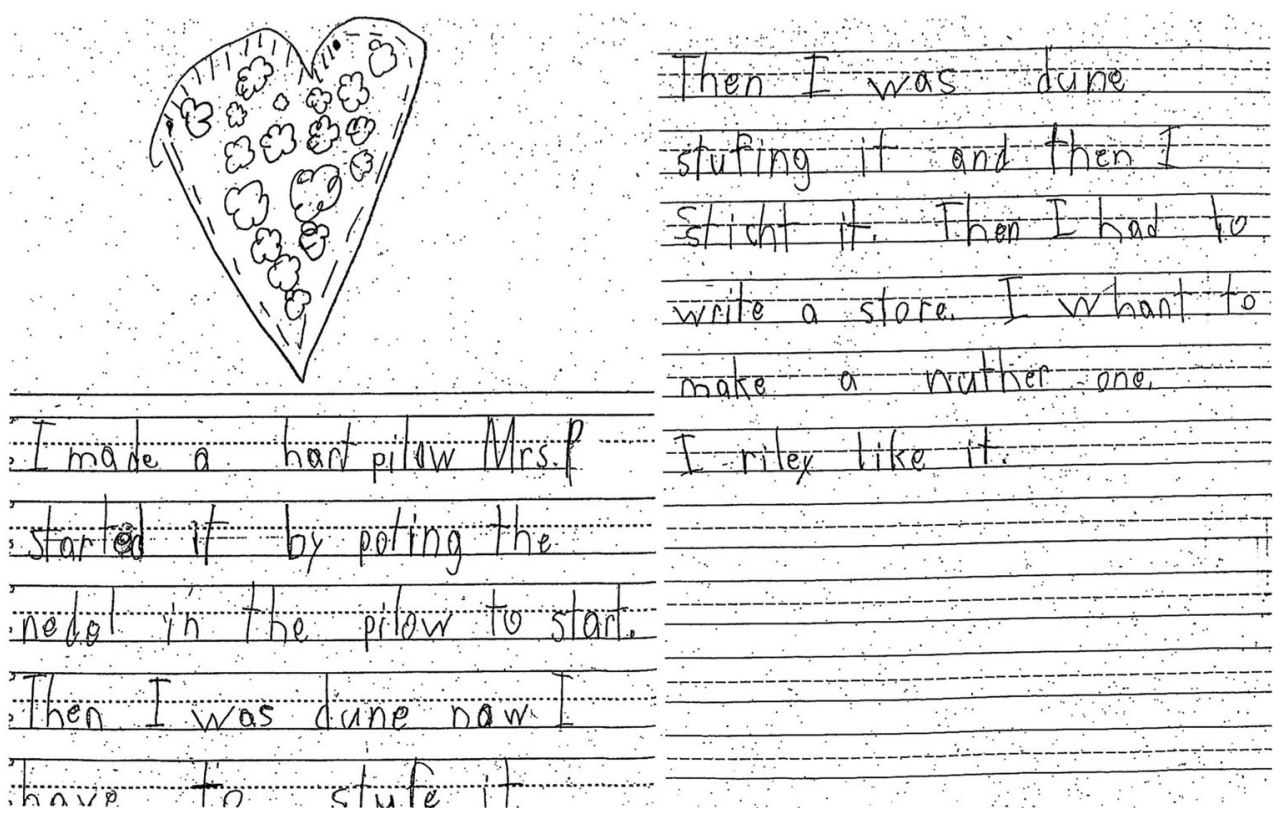

captured by A. Accompanied by a drawing of her and Ad. taking videos (Fig. 3). "First I took a picture of A with the video camera. He was smiling and then I went to take picture of Jack on the computer and he was learning about treefrogs. He was having a good time and then I saw S. He was playing marbles. He liked the marbles." Another child wrote, "In photography I took pictures of blue stuff and interesting stuff and stuff that keeps us safe. When we took pictures of blue stuff we went outside. when we took pictures of interesting stuff we were in the science room upstairs most of the time."
Two children decided to conduct research "I am going to do Resrch today. And I what (want) to do Resrch on mammals." H. choose a hamster to study. Her drawing and accompanying writing is descriptive and answers some short facts about the animal from a worksheet with prompts (Fig. 4).

The following weeks continued with the creation of a lego city, flowerpots, and a nature cart. The lego city was the topic of many conversations with the architects about parts of the city, where different things were located, and suggestions for additions.
Fig. 3 Drawing and narrative of photography and video endeavor

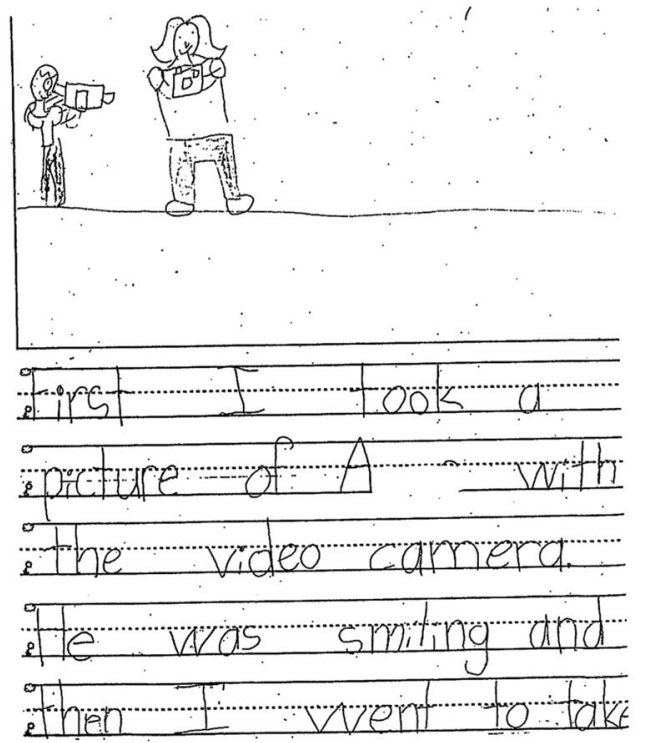




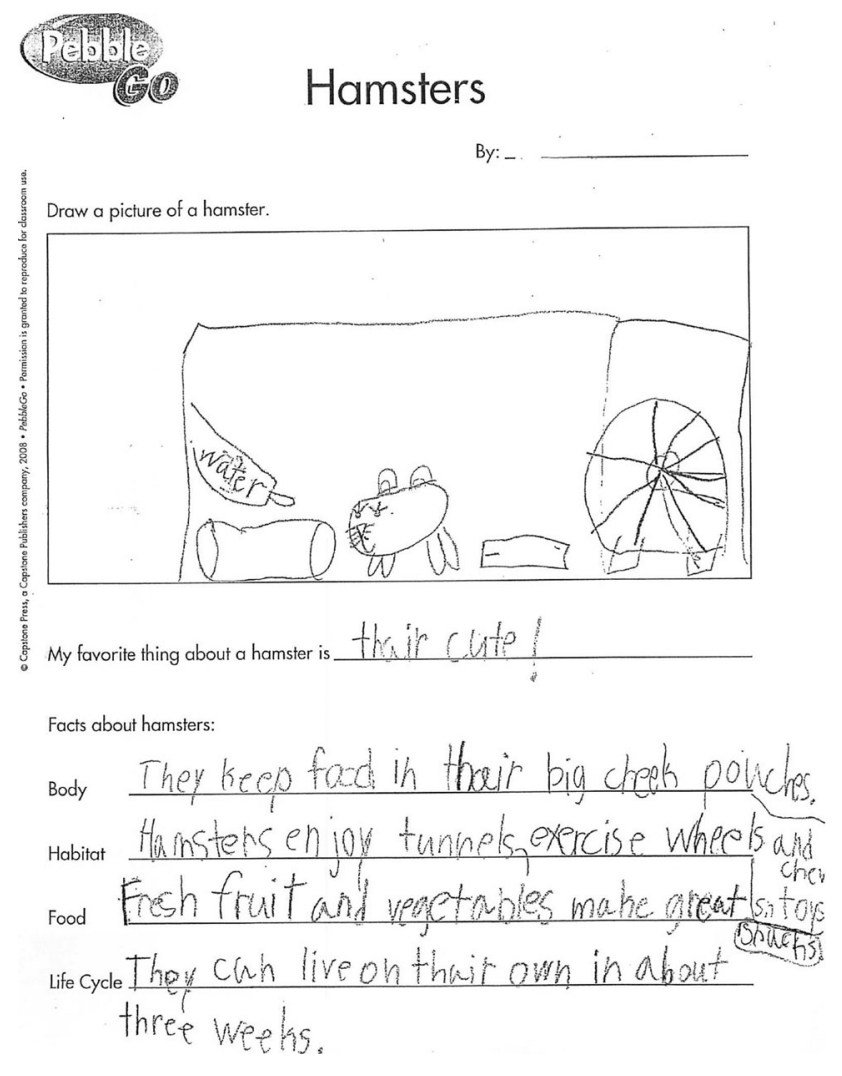

Fig. 4 Drawing and research about hamsters

During this time one group decided to make a play about fairy tales they were reading. After rereading the book they acted it out. Afterwards they made up their own fairy tale to dramatize. As with many fairy tales they often took on a grim tone with a moral embedded therein. S. writes, "I am Master and my friend that is Master Mean. Let's go to the pond at mid night. OK that's fine if I can force my sister to let me go on her birthday. My big tooth is acking (aching) said Master Mean. That makes me want to change my name to Master Cut. Along comes my sister Mary Puppets. Oh her name is Mean girl I said. Sorry that I yelld at you. My sister wants to go now. Master Mean said it should be a surprise party. Let me invite my sister Hots. We said that I should trick her and say it is a party for apologizing."

While this group was busy doing the play, another group was eagerly taking advantage of the digital camera. They created pictures of "winter joy" which the teacher put on a $\mathrm{CD}$ for them to enjoy with their families in the evenings. They also explored shapes around the school that led to a vibrant discussion and exploration of safety features. The group involved with clay continued to work on projects on winter.

\section{Phase Three: Intentional Student Planning and Sharing}

After the first two phases the children began to independently design, construct, and take responsibility for their Creative Endeavor, independently or collaboratively with peers. They began to plan on Fridays with the teacher by writing a proposal for the teacher to find supplies for their next endeavor. Since choice was a key component, but finding supplies could take time, they made plans for at least the whole week, with some children choosing to wait another week before sharing.

Planning of the design, including materials was a key element in the third phase. The children began to formally, in the sense that it was part of the experience rather than an in process conversation, share what they had accomplished either orally in a group or in a written format. The children involved with the yoga cards eagerly shared their accomplished moves with the rest of the class. Those painting pictures explained their techniques to the group. The drama group of course put on their plays, one group created poems and read them aloud to the class, and of course the photographers shared their pictures.

Phase three lasted the remainder of the year. Some projects continued to be popular. Sewing photography, video, and clay were consistently chosen during this very special time of the day.

\section{Conclusion}

Teachers who work with the interests of children, create a natural learning environment. An essential feature of Creative Endeavors was the authenticity of the experiences. As Healy (1990) states, "If we encourage children to make choices from a selected variety of available challenges, both environmental and intellectual, we are no doubt following the wisest course" (p. 72).

Throughout Creative Endeavors, the students had selfefficacy, that is, they believed in themselves. They also had a teacher who believed in them too. The beliefs that that teachers have about their students is critical. Caine and Caine (1997) state,

Teachers' beliefs in and about human potential and in the ability of all children to learn and achieve are critical. These aspects of the teachers' mental models have a profound impact on the learning climate and learner states of mind that teachers create. Teachers need to understand students' feelings and attitudes will be involved and will profoundly influence student learning. (p. 124). 
Through the power of authenticity, choice, and teachers' beliefs, children were motivated to reflect, through drawing and writing, their creative endeavors. When children are involved in learning experiences that are exciting, they become highly engaged (Jones et al. 1994). The research on early writing suggests that when children are using writing to communicate, for authentic purposes they become highly engaged (Goodman and Goodman 1979; Teale 1986; Vernon-Feagans et al. 2003). Students often view writing as a chore, a task, something that is not meaningful. And yet, when students use their experiences to develop written text, they make connections between written language and oral language (McCarrier et al. 2000). The meaningful use of written language was an integral part of Creative Endeavors. As the students formed their writing, they went through a back and forth, or recursive process of developing, changing, and modifying the written message (Calkins 1994; D’Arcy 1989; Graves 1994). The written messages, developed during Creative Endeavors not only supported the various projects the students chose, but added to their learning as they decided how to communicate what they were learning in a written format.

The power of Creative Endeavors is that of an example of how, when, teachers and students negotiate purposeful, meaningful and authentic learning experiences in the classroom everyone benefits. In the presented curriculum, Creative Endeavors have some of the key elements from the research. Appendix 1 includes Tips for Teachers who wish to implement creative activities, and Appendix 2 provides additional teacher resources. Children participated in projects which lasted over the course their needs and interests. The focus was on the process of using artistic forms as symbolic expressions of meaning. It was both a democratic and collaborative curricular approach that emerged under ideal environmental conditions. In addition, the teacher was open to new ideas and functioned both as a model and a mentor. In this way, the teacher was able to see highly motivated, engaged, and joyful students learning what they must to meet curricular standards.

\section{Appendix 1: Tips for Teachers}

\section{How Can Teachers Advocate for Creativity in the Classroom?}

Provide a link to literacy:

- plan for writing as a way for children to plan and to reflect,

- provide children with books for reading to gather ideas,
- ask children to orally share what they have done during the project,

- provide time to have children listen to others about their projects.

\section{What Supplies are Needed?}

The environment should be child-centered. Children should know the basic routines for choosing and using materials. Supplies should be readily accessible. Choice is the key, but as projects develop, materials that might be introduced include:

- a wide variety of art media,

- sewing, knitting, or crocheting materials

- recycled materials,

- technology equipment such as cameras and videocameras,

- books

- internet resources.

\section{How Much Time is Needed to Foster the Experiences?}

Children should feel free to work at their own pace on the project. While the group might all contribute to the ideas, typically each child creates their own project after the initial experience. Time will be limited but, in order to promote creativity, an hour at a time should be allocated. If it is not possible to provide this opportunity every day, alternate schedules could be developed.

\section{What Steps do Teachers Need to Take to Develop Their Own Creative Endeavors?}

- Observe the children as they draw, write, talk, and explore books and magazines to see what media and topics attract their interest.

- Brainstorm ideas with them and discuss media they would like to explore.

- Decide on an initial topic of interest and a variety of media to explore.

- Provide guided practice with groups of children working together on the first project.

- After the first project have children form interest groups based on concepts and media presentations.

- Ask the children to plan what they are going to do in writing in a sentence or two.

- Allow time for children to complete the project.

- Have them provide written reflection about the process, the outcomes, and how they felt about the project.

- Allow groups to share what they have done. 


\section{Appendix 2: Resources for Teachers}

Belz, P. (2011). Using art to teach children about themselves and the world. Exchange: The early childhood leaders' magazine, 199, 34-36.

Teachers know that art activities help students to conceptualize and reconceptualize their world. Art also aids students in communicating in various ways. In this article, Belz makes the case for using art to help students learn about themselves and the world. The ideas presented can easily be used to link art with writing.

Bradshaw. G. The How of Writing: First-Graders Learn Craft. Retrieved from www.nwp.org/cs/nwpp/print/nwpr/ 2188.

Bradshaw shows how to use Arnold Lobel's Frog and Toad books to model various types of writing in the first grade classroom.

Helm, J. H., \& Katz, L. (2001). Young investigators: The project approach in the early years. New York: Teachers College Press.

This book is a great resource for teachers considering a Project Approach to learning. It provides detailed, step-bystep examples of how to organize the early childhood classroom to activate student engagement.

Martens, P., Martens, R., Doyle, M. H., Loomis, J., \& Aghalarov, S. (2013). Learning from picturebooks: Reading and writing multimodally in first grade. The Reading Teacher, 66, 285-294.

This article provides examples how art, especially the art of picture books, can be used to communicate meaning. Students in the first grade class studied used both art and writing to communicate ideas and construct meaning.

Paul, S. Research Writing First Grade Style. Retrieved from http://snippetsbysarah.blogspot.com/.../research-writ ing-first-grade-style.html.

This site provides simple ways to use nonfiction books to scaffold first graders in sharing what they learn in various research formats.

Rantala, T., \& Maatta, K. (2012). Ten theses of the joy of learning at primary schools. Early Child Development and Care, 182, 87-105.

The researchers in this study looked at the responses of first and second grade learners to determine their joy or lack thereof to various learning experiences. Based on these observations, a list of ten theses were developed that highlight elements in the classroom that teachers can use to provide for joyful learning.

Udvari-Solner, A., \& Kluth, P. M. (Eds.) (2007). Joyful learning: Active and collaborative learning in inclusive classroom. Newbury Park, CA: Corwin.

A practical book written to assist the teacher in working with the diverse learners in the K-12 classrooms. Examples are given throughout as to how to promote active and collaborative classroom activities that address student differences in ability, language, and culture.

\section{References}

Caine, G., \& Caine, R. N. (1997). Education at the edge of possibility. Alexandria, VA: Association for Supervision and Curriculum Development.

Calkins, L. M. (1994). The art of teaching writing (rev. ed.). Portsmouth, NH: Heinemann.

Connors, A. (2013). The sound of creativity: Rhythm instrument activities can help young children develop creative thinking skills. Teaching Music, 21(1), 30-32.

D’Arcy, P. (1989). Making sense, shaping meaning: Writing in the context of a capacity-based approach to learning. Portsmouth, NH: Heinemann.

Edwards, C., Gandini, L., \& Forman, G. (1998). The hundred languages of children. Westport, CT: Ablex.

Glaveanu, V. (2010). Principles for a cultural psychology of creativity. Culture and Psychology, 16(147), 147-163.

Goodman, K., \& Goodman, Y. (1979). Learning to read is natural. In L. Resnick \& P. Weaver (Eds.), Theory and practice of early reading (Vol. 1, pp. 137-154). Hillsdale, NJ: Erlbaum.

Graves, D. H. (1994). A fresh look at writing. Portsmouth, NH: Heinemann.

Healy, J. M. (1990). Endangered minds. New York: Simon Schuster.

Helm, J. H. (2008). Got standards? Don't give up on engaged learning. Beyond the Journal, Young Children on the Web. Retrieved from http://www.naeyc.org/files/yc/file/200807/BTJJu dyHarrisHelm.pdf.

Jones, B., Valdez, G., Nowakowski, J., \& Rasmussen, C. (1994). Designing learning and technology for educational reform. Oak Brook, IL: North Central Regional Educational Laboratory.

McCarrier, A., Pinnell, G. S., \& Fountas, I. C. (2000). Interactive writing: How language and literacy come together, $K-2$. Portsmouth, NH: Heinemann.

McPake, J. (2013). Pre-school children creating and communicating with digital technologies in the home. British Journal of Educational Technology, 44(3), 421-431.

Miranda, M. (2015). Moving off the page: Tapping into young children's imagination. General Music Today, 28(2), 33-35.

National Advisory Committee on Creative and Cultural Education, Robinson, K. (Chair). (1999). All Our Futures: Creativity, Culture \& Education. London: DFEE. Retrieved from www. creativitycultureeducation.org.

Nichols, S., \& Berliner, D. (2008). Testing the joy out of learning. Educational Leadership, 65(6), 14-18.

Sharp, C. (2004). Developing young children's creativity: What can we learn from research? UK: National Foundation for Educational Research. Retrieved from www.infer.ac.uk/publications/ 55502/55502.pdf.

Sharp, C., Pye, D., Blackmore, J., Brown, E., Eames, A., Easton, C., et al. (2006). National evaluation of creative partnerships final report. United Kingdom: National Foundation for Educational Research.

Tanggard, L. (2011). Stories about creative teaching and productive learning. European Journal of Teacher Education, 34(4), 219-232.

Teale, W. (1986). Home background and young children's literacy development. In W. Teale \& E. Sulzby (Eds.), Emergent 
literacy: Writing and reading (pp. 173-206). Norwood, NJ: Ablex.

Vernon-Feagans, L., Hammar, C., Miccio, A., \& Manlove, E. (2003). Early language and literacy skills in low-income African American and Hispanic children. In S. Neuman \& D. Dickinson (Eds.), Handbook of early literacy research (Vol. 1). NY: Guilford Press.

Ward, G., \& Dahlmeier, C. (2011). Rediscovering joyfulness. Young Children, 66, 94-98. Retrieved from http://www.nxtbook.com/ nxtbooks/naeyc/youngchildren_201111/index.php?startid=94\& $\mathrm{qs}=$ Rediscovering + Joyfullness $\# / 96$.

Webb, A. (2012). Developing second graders' creativity through literacy-science integrated lessons on lifecycles. Early Childhood Education Journal, 40(6), 379-385. 